\title{
LETTER
}

\section{An expected association between low haemoglobin and poor outcome in severe head injury and an insufficiently detailed multivariate analysis}

\author{
Kieran Donnelly* \\ See related research by Sekhon et al., http://ccforum.com/content/16/4/R128
}

I read with interest the paper by Sekhon and colleagues, 'Association of hemoglobin concentration in critically ill patients with severe traumatic brain injury' (July edition of Critical Care) [1]. Whilst the conclusion ('mean 7-day haemoglobin concentration $<90 \mathrm{~g} / \mathrm{L}$ associated with increased hospital mortality in patients with severe traumatic brain injury') is striking, it is plausible, if not likely, that both the haemoglobin deficit and the observed mortality are dependent upon the severity of the initial injury, and therefore an association between these two might be expected.

Given the lack of transfusion trigger and a target haemoglobin concentration post-transfusion in this study, and a generous group upper limit of $90 \mathrm{~g} / \mathrm{L}$, would those patients with the lowest initial haemoglobin concentration not be likely to stay below that threshold despite transfusion? Are not the most severe injuries also likely to be associated with a 7-day mean haemoglobin of less than $90 \mathrm{~g} / \mathrm{L}$ ?

Injury severity was reportedly accounted for in the multivariate analysis, although the details of the model used were not given. What weighting was given to each variable, such as Glasgow Coma Scale, or CT appearance, and on what basis? Of note is the lack of information regarding other injuries, not just in the multivariate analysis but indeed the entire paper. Were only isolated head injuries considered or were polytrauma patients included in this study?

To accept that more than an association exists between two variables - as implied - we must be satisfied of the validity of the multivariate analysis.

\section{Authors' response}

Donald EG Griesdale, Mypinder S Sekhon, Nielson McLean, William R Henderson and Dean R Chittock

We thank Dr Donnelly for his careful critique of our manuscript [1]. We agree with his assertion that hemoglobin concentration and mortality may be confounded by the severity of illness. In the manuscript, we devote considerable time discussing bias in the context of our results. Despite these concerns, the baseline patient characteristics were remarkably similar between exposure levels. Thus, measured baseline characteristics would be unlikely to account solely for the observed mortality in our study. Although as mentioned in our

*Correspondence: kdonnelly2@nhs.net

Department of Anaesthetics, Queen Elizabeth Hospital, Edgebaston, Birmingham, B15 2TH, UK

BioMed Central o 2013 Biomed Central Ltd discussion, we would be unable to account for unmeasured covariates, which could be a significant source of confounding.

Another concern expressed by Dr Donnelly was the details of the model building. All covariates included in the final model were chosen a priori based on subject matter knowledge [2]. Age and admission Glasgow Coma Scale were included in the final model as these are known strong predictors of outcome in traumatic brain injury [3]. Additionally, we included red cell transfusion as did other studies in the area $[4,5]$. Insertion of an external ventricular drain was chosen because of its association with mortality in our prior study of the same cohort [6]. Although additional variables could have been included in the final model (for example, CT appearance), we were limited in the number of covariates included in the final 
model due to few outcome events present in the study [7]. His question as to the weighting of covariates is unclear. With respect to the modeling itself, all observations were equally weighted.

We disagree with Dr Donnelly's assertion that we implied '...more than an association exists...' between hemoglobin concentration and mortality. Our conclusions were presented in a measured fashion with a careful discussion of the limitations. Despite these limitations, observational studies remain important tools to help generate hypotheses and guide further study design.

\section{Competing interests}

The author declares that they have no competing interests.

Published: 11 January 2013

\section{References}

1. Sekhon MS, McLean N, Henderson WR, Chittock DR, Griesdale DE: Association of hemoglobin concentration and mortality in critically ill patients with severe traumatic brain injury. Crit Care 2012, 16:R128.

2. Greenland S: Modeling and variable selection in epidemiologic analysis. Am J Public Health 1989, 79:340-349.

3. Perel P, Arango M, Clayton T, Edwards P, Komolafe E, Poccock S, Roberts I, Shakur H, Steyerberg E, Yutthakasemsunt S: Predicting outcome after traumatic brain injury: practical prognostic models based on large cohort of international patients. BMJ 2008, 336:425-429.

4. Salim A, Hadjizacharia P, DuBose J, Brown C, Inaba K, Chan L, Margulies DR: Role of anemia in traumatic brain injury. J Am Coll Surg 2008, 207:398-406.

5. Carlson AP, Schermer CR, Lu SW: Retrospective evaluation of anemia and transfusion in traumatic brain injury. J Trauma 2006, 61:567-571.

6. Griesdale DEG, McEwen J, Kurth T, Chittock DR: External ventricular drains and mortality in patients with severe traumatic brain injury. Can J Neurol Sci 2010, 37:43-48.

7. VittinghoffE, McCulloch CE: Relaxing the rule of ten events per variable in logistic and Cox regression. Am J Epidemio/ 2007, 165:710-718.

doi:10.1186/cc11879

Cite this article as: Donnelly K: An expected association between low haemoglobin and poor outcome in severe head injury and an insufficiently detailed multivariate analysis. Critical Care 2013, 17:404. 